\title{
A CONSTRUÇÃO DOS VALORES NO AMBIENTE ESCOLAR: UM ESTUDO DE CASO
}

\author{
Márcia Spíndola | spindolamarcia2@yahoo.com.br \\ Professora de Matemática, coordenadora de Estágio Supervisionado IV, Licenciaturas EAD/UERJ.
}

Silvia Helena Mousinho | silviamousinho@yahoo.com.br

Professora de Física, coordenadora de Estágio Supervisionado III, Licenciaturas EAD/UERJ.

\section{Resumo}

No atual contexto da globalização, caracterizado pela mundialização neoliberal, a sociedade exige cada vez mais indivíduos dotados de poder de decisão e iniciativa. Um novo olhar nos encaminha a novas práticas educativas e a ressignificar o papel do professor. Reconhecendo a complexidade das relações humanas quando a prioridade é educar em direção à autonomia, esse trabalho, através das concepções de Piaget sobre o desenvolvimento moral na criança, faz considerações sobre a importância de educar em valores. Cabe salientar que as contribuições de Piaget foram essenciais para a compreensão do desenvolvimento da moralidade, e a subjetividade inerente a esse objeto de estudo tem favorecido a integração de áreas afins em uma dimensão complementar. Não existem conteúdos específicos para trabalhar valores, e o seu caráter de natureza abstrata e não diretiva requer uma visão holística do conceito de educação para que tenhamos êxito em nosso propósito. No indissociável binômio teoria/prática, o objetivo maior do educador é possibilitar que o aluno construa a sua própria escala de valores, baseado na reflexão crítica sobre as condições humanas e que, ao longo desse processo, na conquista de sua autonomia, ele perceba que cabe ao homem a tomada de decisões diante das situações que comprometam a sua sobrevivência e a sua qualidade de vida. O presente trabalho pretende chamar a atenção para uma educação que nos desafia a repensar os rumos que a escola e nós, educadores, temos de assumir para educar visando à inteireza do ser humano. A nossa proposta é criar um espaço de reflexão a partir de um estudo de caso que, frequentemente, ocorre no nosso cotidiano profissional.

\section{Palavras-chave}

Prática docente. Educação em valores. Autonomia na aprendizagem. 
THE CONSTRUCTION OF VALUES IN THE SCHOOL ENVIRONMENT: A CASE STUDY

\section{Abstract}

In the current globalization environment, pervaded by neo-liberal thinking, our society requires that more and more individuals be endowed with decision-making skills and initiative. A new outlook leads us to new educational practices and thus to reappraise the educator's role. Recognizing the complexity of human relations when the goal is to educate the learner towards autonomy, through Piaget's concepts relating to the moral development of the infant, this paper considers the importance of educating for moral values. It is well to note that Piaget's contributions proved essential to an understanding of the development of morality, and the subjectivity inherent in this object of study has favored the integration of related areas in a complementary dimension. There are no specific contents to work with values and their abstract and non-directed nature call for a holistic view of education if we are to succeed in our purpose. In the indissociable theory/ practice binomial, the educator's greater objective is to allow the student to build his own value scale, based on a critical reflection on the human condition, and as he conquers his autonomy along this process, help him realize that it is up to man to make decisions when faced with situations that compromise his survival and his life quality. The present work aims to call attention to a type of education that challenges us to rethink the role that school, and we as educators, must have so as to educate aiming at the whole human being. We propose to create a reflection space from a case study which frequently takes place in our professional daily lives.

\section{Keywords}

Teaching. Educating for values. Learning autonomy.

\section{Introdução}

A educação e o ensino, sob uma visão cartesiana, não preparam o educando de hoje para a vida em sua plenitude. Fica claro que o nosso papel vem sofrendo transformações significativas, já não é o bastante ter frequentado a universidade e aprofundado os estudos em uma dada disciplina para lecioná-la.

Vivemos em um mundo globalizado $e$ fazemos parte de uma sociedade altamente complexa, de tendências ideológicas neoliberais, cuja tônica é a conjugação do verbo "ter".

Nos dias de hoje, o exercício da cidadania acaba se reduzindo apenas à realização de um trabalho profissional com o objetivo de ganhar a vida (grifo nosso). Para a economista Hazel Henderson, "priorizando esse propósito, estamos glorificando algumas de nossas predisposições humanas menos louváveis: cobiça material, competitividade, orgulho, egoísmo e ganância" (in Capra, 1995, p. 193). Com muita propriedade, Erich Fromm nos aponta que "a falta de discernimento entre o senso de ser e a possibilidade de ter nos torna suscetíveis à manipulação de nossos desejos e do sentido profundo de nossas vidas" (1986, p. 25).

A realidade nos aponta a necessidade de ampliar o nosso fazer profissional e a sensibilidade muito nos ajuda nesse sentido. A educação do futuro, para o pensador Edgar Morin, deve ter como prioridade "ensinar a condição humana, onde o ser humano é a um só tempo físico, biológico, psíquico, cultural, social e histórico" (2003, p. 15).

É no ambiente escolar, através das vivências cotidianas nesse microcosmo que o aluno incorporará princípios básicos de justiça, tolerância, solidariedade, amor e respeito pelos direitos e deveres e, futuramente, reproduzirá essas posturas na sociedade e no mundo em que vive. Se quisermos educar para a compreensão humana, teremos de educar em valores, em convicções e em atitudes. E o professor tem um papel crucial nessa formação.

\section{A construção dos valores}

Segundo Gadotti (2004), para "ser professor hoje é preciso viver intensamente o seu tempo com consciência e sensibilidade" (p. 4). A educação deve ser concebida como um processo de aprendizado e emanci- 
pação para que a construção do conhecimento integre todas as dimensões do ser humano: corpo/mente/ sentimento. Mas, geralmente, a escola ainda valoriza a capacidade cognitiva acima das outras qualidades humanas, embora saibamos que a inteligência, isoladamente, não constitui o valor de um homem.

$\mathrm{O}$ homem faz uso do discurso para dizer o que pensa, mas é através de suas ações que ele revela o que sente. Portanto, se pretendemos trabalhar com valores morais, não é no nível do intelecto que o professor deve atuar, mas no nível dos sentimentos e das emoções. Porém não existe uma atividade específica para isso. Trata-se de uma questão de atitude, uma atenção constante que permeia todas as disciplinas, valoriza todos os momentos - a hora do recreio, a hora do bate-papo, a vida escolar em sua plenitude.

Em síntese, como sensibilizar o nosso aluno para as questões éticas e humanísticas? Sabemos que não é através de livros ou discursos. No máximo, eles vão aprender a repetir o que leram e tirar boas notas na prova. Por acaso haverá prova de valor moral?

No cotidiano do ambiente escolar, pequenos conflitos interpessoais apontam a importância e a necessidade da existência de regras que visem à garantia do convívio social. Nessas ocorrências cotidianas, dependendo da forma como o professor lida com a situação e a sua concepção de disciplina e educação, os conflitos, naturais em qualquer relação, são vistos como uma oportunidade para trabalhar valores e regras.

A construção dos valores morais tem início, desde a mais tenra idade, quando a criança começa a interagir com os mais diversos ambientes sociais. A partir da relação familiar, as interações sociais com os seus colegas e com os profissionais envolvidos na comunidade escolar contribuirão para o desenvolvimento e a formação da personalidade do indivíduo que expressará de acordo com a construção de sua tábua de valores o seu senso moral e a sua consciência moral através de suas ações.

Para educar em direção à consciência moral autônoma, Piaget faz considerações sobre a importância de educar em valores. Em sua obra $\mathbf{O}$ juízo moral na criança, ele estuda o processo de construção da moralidade na criança, mostrando que enquanto ela organiza o pensamento e o julgamento, podemos ob- servar três estágios de desenvolvimento e as atitudes dominantes de acordo com a idade.

Segundo Piaget, a criança passa por uma fase pré-moral, caracterizada pela anomia (A: negação; nomia: regra, lei), coincidindo com o "egocentrismo" infantil e que vai até, aproximadamente, 4 ou 5 anos de idade. No período sensório-motor, não existem regras, são as necessidades básicas que determinam as normas de conduta. Quando a criança atinge 7 ou 8 anos de idade, tem início a fase da moralidade heterônoma, caracterizada pelo comportamento de submissão às regras e aos deveres impostos coercitivamente. Nesse período, ela compreende as regras como sagradas porque quem as informa é o adulto, cuja superioridade é para ela inquestionável e inatingível.

Na relação estabelecida entre a criança e os adultos, particularmente, os pais, nasce a obediência por medo da punição. A noção de responsabilidade pelos atos é avaliada de acordo com as consequências objetivas das ações, e não pelas intenções. A relação estabelecida entre a criança e os mais velhos é o protótipo das relações coativas.

Em torno de 11 ou 12 anos, a criança é capaz de avaliações morais pessoais e, em certos casos, ela entra em conflito com os sentimentos da moral heterônoma da obediência por perceber que mudar uma regra deixa de ser uma transgressão. Nesse momento, tem início o processo de passagem da moral heterônoma para a moral autônoma.

Para Piaget (1933/1977), a personalidade autônoma é o produto mais refinado da socialização (p. 245) porque é somente em uma relação de respeito mútuo entre personalidades autônomas que é possível, simultaneamente, a diversidade e a igualdade. Mas, da mesma forma que nem todo indivíduo atinge o pensamento formal, nem todos chegam a formar uma personalidade autônoma; pelo contrário, "a consciência adulta autônoma é um produto social recente e excepcional" (PIAGET, 1944/1977, p. 186).

Piaget também chama a atenção para o fato de que sem que se estabeleçam trocas do sujeito com o meio não há nem conhecimento nem ética possíveis. E que o desenvolvimento intelectual, isto é, a possibilidade de raciocínio lógico, a relação de res- 
peito mútuo com o outro e a constituição de uma tábua de valores são condições necessárias para a conduta moral e ética.

$\mathrm{Na}$ moralidade autônoma (autonomia: capacidade de governar a si mesmo), o indivíduo adquire a consciência moral, e os deveres são cumpridos com o reconhecimento de sua necessidade e significação. $\mathrm{Na}$ ausência da autoridade continua o mesmo, segue um código de ética interno, fiel a seus valores e a seus princípios. A responsabilidade é subjetiva, baseada na intencionalidade do ato, ou seja, é aquela em que o indivíduo atinge seus objetivos através de uma intenção deliberada.

Sob uma perspectiva holística, podemos observar que os valores, ao mesmo tempo que estão relacionados intimamente à formação do indivíduo, também são eleitos e emergentes da cultura e/ou da sociedade a que cada indivíduo pertence (GRINSPUN, 1999).

Para que um professor possa ser um educador em valores, é condição essencial ser ele mesmo um exemplo de tudo o que transmite através de suas ações e de sua postura. Pierre Weil (1993) nos desafia com suas reflexões a esse respeito quando afirma que:

em sua formação também seria importante cultivar nos educadores uma disposição para trabalhar suas essências. Além disso, que eles sejam suficientemente lúcidos para viver a arte da atenção em si mesmos e serem honestos para mostrar como são para si próprios. Desejamos ainda que esses educadores sejam levados a apresentar freqüentemente atitudes e comportamentos ligados aos valores humanos: verdade, beleza e amor (p. 41).

A educação tem tido um papel de socialização do conhecimento, da cultura e dos valores em todas as sociedades e em todos os tempos. O comportamento humano e o posicionamento de cada indivíduo frente aos valores e princípios, em um determinado momento de sua vida, não têm um caráter definitivo. Segundo Arruda (1998), os valores são, num primeiro momento herdados por nós. Para construir a sua própria escala de valores, a criança ou o adolescente precisa do referencial do mundo adulto.

Não nos cabe aqui um aprofundamento sobre o conceito filosófico do que se entende por valor. O que pretendemos é focalizar a nossa atenção para a necessidade de uma educação que eduque, também, em valores que estruturam as relações interpessoais e in- trapessoais. Sendo assim, em uma perspectiva psicossocial, Novikoff (2002) faz uso da seguinte classificação dos valores básicos, essenciais para a convivência humana em sociedade:

- Valores pessoais: inclui as representações qualitativas sobre as pessoas, incluindo as questões éticas.

- Valores econômicos: refletem os objetos materiais ligados ao consumo/utilidade.

- Valores espirituais: apontam os valores estéticos e os religiosos.

Os valores estão referendados aí pelo senso moral e pela consciência moral - justiça, solidariedade, generosidade, integridade, honestidade e outros. Os valores provam ainda sentimentos de vergonha, culpa, admiração, amor, dúvida, contentamento, cólera, medo, que interferem em nossas decisões nos levando a ações que atingirão a nós mesmos e aos outros.

\section{Marilena Chaú (1999) com sensibilidade esclarece que}

(...) Os sentimentos e as ações, nascidos de uma opção entre o bom e o mau ou entre o bem e o mal, também estão referidos a algo mais profundo e subentendido: nosso desejo de afastar a dor e o sofrimento e de alcançar a felicidade, seja por ficarmos contentes conosco mesmo, seja por recebermos a aprovação dos outros. Portanto, o senso e a consciência moral dizem respeito a valores, sentimentos, intenções, decisões e ações referidas ao bem e ao mal e ao desejo de felicidade (p. 335).

Os valores apontados devem atravessar os limites disciplinares e permear o cotidiano do aluno. Considerando que alguns conceitos são demasiadamente abstratos, é fundamental estimular através de dinâmicas e experiências concretas a vivência de situações que favoreçam o processo de identidade pessoal, pois, assim, podemos identificar que valores estão sendo privilegiados naquela circunstância. As ciências do comportamento contribuem, significativamente, para uma melhor compreensão do desenvolvimento da moralidade na criança e no adolescente e de como se dá o processo da legitimação dos valores e das regras morais.

Quando estamos diante de uma decisão a tomar, as nossas dúvidas manifestam não só o nosso senso moral, mas colocam à prova a nossa consciência moral, pois exigem que façamos uma escolha, que justifiquemos para nós mesmos e para os outros as razões de nossas opções e que assumamos todas as consequências decorrentes de nossos atos. Portan- 
to, a consciência moral é o resultado operativo de nosso senso moral (CHAUÍ, 2000).

Sabemos que uma pessoa capaz de agir eticamente nem sempre de fato o faz. Assim como uma pessoa capaz de raciocinar logicamente nem sempre pensa de acordo com as normas lógicas. Piaget deixou intocado o mistério de por que mesmo uma pessoa que tenha as condições necessárias para a ação moral nem sempre age eticamente (FREITAS,1999).

Na verdade, não é possível definir precisamente de que modo uma pessoa chega a legitimar determinadas normas de comportamento e conduzir-se de acordo com elas de maneira coerente. Sabemos que um conjunto de processos conscientes e inconscientes, ao longo de toda a vida, forma o nosso perfil individual. $\mathrm{O}$ modo como se dão o ensino e a aprendizagem, isto é, as opções didáticas, os métodos, a organização e o âmbito das atividades, a organização do tempo e do espaço na prática educativa, ensina valores, atitudes e conceitos. E a escola deve ser o lugar onde cada aluno reconheça que os valores e as regras são coerentes $e$ passíveis de uma identidade pessoal ante a perspectiva de uma vida plena e feliz.

\section{Um estudo de caso}

Partindo da concepção de que os valores estão presentes nas opções individuais e são referendados em todos os âmbitos da vida no cotidiano nas dimensões social, histórica, cultural, afetiva, política, econômica, cabe aqui indagar: qual é o papel da escola como referencial para o aluno na construção de sua escala de valores? Como estabelecer ações e estratégias para consolidar essa formação no momento atual? Que valores queremos transmitir em nossas escolas? E estes valores estariam relacionados somente ao ambiente escolar? De que forma podemos criar um espaço sistemático de discussão sobre valores no ambiente escolar com a participação da comunidade escolar? Vamos focalizar um caso que permeia o nosso cotidiano profissional e nos coloca à prova ante essas indagações. Durante a aula, um aluno visivelmente maior agride um colega pelo fato de o mesmo ter usado o seu estojo de canetas sem autorização. O professor intercede e pede que, ao término da aula, ambos o aguardem na coordenação. Qual seria o procedimento mais adequado diante dessa situação?
Afastando situações atípicas, os conflitos mais comuns no ambiente escolar, são: agressão física entre os alunos, rejeição por parte dos colegas ou dos professores (proibição de participação) e conflitos verbais (ofensas, provocações).

$\mathrm{Na}$ escola tradicional, as desavenças e os atritos entre as crianças são tratados como problemas a serem extintos a qualquer custo. É importante ressaltar que, na maioria das vezes, os conflitos são vistos como nocivos e negativos. Piaget concebe os conflitos interpessoal e intrapessoal como necessários ao desenvolvimento porque através do processo de desequilibração o sujeito é motivado a buscar uma nova ordem interna.

Os cursos de formação de profissionais em educação não preparam o futuro profissional para lidar com os conflitos que ocorrem nas instituições de educação. Para que o comportamento se enquadre no modelo que prioriza a obediência, as punições e as recompensas são as práticas adotadas: proibir uma atividade que dá prazer ao aluno, tirar ponto, suspender, fazer sermão, ameaçar etc. Nesse ambiente, as relações coercitivas se expressam através da valorização do poder hierarquizado, o que pressupõe uma educação que alimenta as atitudes interiores que predispõem o indivíduo na fase heterônoma, tais como medo, imposição, autoritarismo, castigo, prêmio, respeito unilateral, tirania. Consequentemente, contrariando o princípio democrático da liberdade, o máximo que se consegue é que as pessoas tenham comportamentos adequados (grifo nosso) quando estão sob controle, o que é essencialmente diferente se queremos educar para a autonomia.

Se a professora se dirige ao agressor perguntando o porquê de ele ter agredido o colega, se ele gostaria que fosse com ele, e sugere um pedido de desculpas, embora a intenção seja cabível e louvável, a intervenção da professora elimina a possibilidade de o menino (agredido) se expressar e aprender a falar por si próprio sobre o que o incomodou perante o agressor. Essa é uma questão corriqueira no dia a dia das crianças nas escolas, e cabe chamar a atenção para o fato de que, na busca de sua própria defesa, a criança é estimulada a fazer uso de suas próprias palavras e a participar da resolução do problema. A professora, em vez de resolver com autoridade a situ- 
ação, pode contribuir para que ambos reflitam sobre o caso, atenta aos sentimentos que eles estão expressando naquele instante. Essa pode ser uma oportunidade para reconhecer as tendências de reação das crianças e o momento pode ser favorável à valorização do respeito pelo outro. A professora poderá ainda intervir explicitando o problema, ajudando-os a perceber a importância de controlar os impulsos de raiva e que a agressão física não é a melhor maneira de resolver as dificuldades com os colegas. Cabe também à professora chamar a atenção para o abuso da superioridade física, apontando para um possível ato de covardia. Nessa situação e em inúmeras outras similares, percebemos que a orientação de um professor habilidoso é capaz de promover um ambiente, em sala de aula, de cooperação e afetividade de democracia e de interação com os alunos, propiciando a troca de ideias e opiniões, o exercício da argumentação, a análise e proposta de soluções etc. Portanto, o modo como os conflitos sociomorais são resolvidos em sala de aula torna-se um excelente aliado para se trabalhar regras, princípios e valores.

Não visando apenas à resolução do conflito, a conduta da professora é um procedimento mais coerente com a construção da autonomia. Como afirma Menin (1996, p. 61), "quer queiram ou não, todas as escolas atuam na formação moral de seus alunos; no entanto, nem todas o fazem na direção da autonomia".

As professoras Montserrat Moreno e Genoveva Sastre (2002) apontam que é fundamental que o professor desafie os alunos na direção da resolução dos conflitos a fim de conduzi-los permanentemente a:

- buscar soluções próprias;

- analisar as soluções apresentadas, antecipando suas consequências e observando se estas levam ao resultado esperado;

- investigar as relações entre as causas e os conflitos apresentados;

- considerar o que é uma boa solução para um determinado conflito;

- pensar que as soluções para os conflitos devem ser justas, caso contrário, podem acarretar mais conflitos.
É de suma importância reconhecer que a escolha da conduta mais adequada perpassa pela qualidade da relação professor/aluno constituída. Nessa relação estão implícitos, por exemplo, o papel do professor como referencial para o aluno na construção de seus princípios éticos e morais, a sensibilização do aluno para as questões éticas e humanísticas, a educação em atitude e em direção à autonomia etc.

\section{Considerações finais}

Apesar de a realidade escolar evidenciar a necessidade de educar para a resolução de conflitos sociomorais, as instituições responsáveis pela formação dos professores não investem em seus programas curriculares nessa modalidade de conhecimento. Consequentemente, a educação nas dimensões moral e ética é legada ao improviso e ao acaso.

As práticas pedagógicas que auxiliam no desenvolvimento da moralidade devem ser constituídas desde atividades de rotina na sala de aula até a seleção de conteúdos que promovam esse desenvolvimento. Portanto, ao se trabalhar com a construção de valores, assim como nos demais conhecimentos, "a realização dos objetivos propostos implica necessariamente que sejam desde sempre praticados, pois não se desenvolve uma capacidade sem exercê-la" (BRASIL, 1997, p. 94).

A educação, quando concebida como um processo de aprendizado ao longo de nossa existência, rompe as fronteiras demarcadas pela disciplinarização. Uma aula de qualquer disciplina pode e deve ter abertura para tomar qualquer direção, atravessando diferentes campos de conhecimento sem a identificação com apenas um deles. Essa interdependência leva à imprevisibilidade que desmitifica a obrigatoriedade de seguir apenas por caminhos predefinidos. É no espaço sagrado de nossa sala de aula que enveredamos magicamente por todos os caminhos imagináveis e inimagináveis que a mente humana pode alcançar. Essa experiência ímpar e enriquecedora cria condições favoráveis para que se estabeleçam diálogos abertos e os alunos experimentem a liberdade de opinar e expressar suas ideias com autoconfiança. Uma educação com tais características é o que verdadeiramente podemos chamar de educação conscientizadora e transformadora. 
O maior desafio para nós, profissionais de educação, é articular um trabalho nas diferentes áreas de conhecimento que encaminhe a prática educativa objetivando reflexões sobre os princípios que fundamentam os valores. E que, ao longo desse processo, na conquista de sua autonomia, o aluno perceba que cabe a ele tomar decisões diante de situações que comprometam a sua qualidade de vida e a sua sobrevivência. Embora a família e outras instituições sociais veiculem valores e desempenhem um papel significativo no desenvolvimento moral e na formação de atitudes do aluno, a escola é o lugar onde esses valores são pensados, refletidos e dialogados.

No atual contexto da globalização, a sociedade exige cada vez mais indivíduos dotados de poder de decisão $e$ iniciativa. A fragilidade dos laços familiares e sociais compromete o processo de individuação do jovem $e$ do adolescente cujas dificuldades emocionais são marcadamente difusas. $\mathrm{O}$ ato de aprender pressupõe uma relação com outra pessoa, a que ensina. É essencial que o professor esteja atento às transformações pelas quais está passando a estruturação emocional do adolescente de hoje. A liberação dos usos e costumes, assim como a diminuição das barreiras e proibições entre as gerações, é causadora de sérios problemas de estruturação psíquica durante a adolescência. Sob a perspectiva psicanalítica, a relação que se estabelece entre o professor e seu aluno é que determina as condições para aprender, sejam quais forem os conteúdos. É necessário uma atuação do professor para que o aluno atribua um sentido especial à sua figura e seja estimulado no seu desejo de saber e aprender.

"A Construção dos Valores no Ambiente Escolar: um estudo de caso", através da análise e reflexão sobre a experiência cotidiana, aponta novos caminhos ao propor um modo mais adequado e eficiente de lidar com questões que permeiam o cotidiano do professor. No dia a dia de nossa profissão são muitas as situações que vivenciamos, tanto no âmbito da relação professor/aluno quanto no universo das relações com profissionais de educação que, a exemplo do caso em estudo, se aprofundadas com aporte teórico, contribuiriam para qualificar a nossa prática profissional, estreitando e valorizando sempre a relação teoria/prática com sabedoria. 


\section{Referências bibliográficas}

ARAÚJO, Ulisses F. O sentimento de vergonha como um regulador moral. 1998. Tese (Doutorado) - IP, Universidade de São Paulo, São Paulo, 1998.

BRASIL, Secretaria de Educação Fundamental. Introdução aos Parâmetros Curriculares Nacionais. Brasília: MEC/SEF, 1997.

CAPRA, Fritjof. Sabedoria incomum. 10. ed. São Paulo: Cultrix, 1995.

CHAUÍ, Marilena. Convite à filosofia. São Paulo: Ática, 2000.

FREITAS, L.B.L. Do mundo amoral à possibilidade de ação moral. Psicologia: reflexão e crítica, n. 12, p. 447-458, 1999.

FREITAS, L.B.L. A moral na obra de Jean Piaget: um projeto inacabado. 1997. Tese (Doutorado) - Curso de Pós-Graduação em Psicologia, Universidade de São Paulo, São Paulo, 1997.

FROMN, Erich. Do amor à vida. Rio de Janeiro: Jorge Zahar, 1986.

GADOTTI, Moacir. Boniteza de um sonho: ensinar e aprender com sentido. Rio de Janeiro: Feevale, 2004.

GRINSPUN, Mírian Paura S. Zippin; NOVIKOFF, Cristina. Os adolescentes e a construção dos valores. Rio de Janeiro: Universidade do Estado do Rio de Janeiro, UERJ, 1999. Projeto de Pesquisa.

GRINSPUN, Mírian Paura S. Zippin. Os valores do jovem no contexto atual. Rio de Janeiro: Universidade Estadual do Rio de Janeiro, 1999. Projeto de pesquisa.

MENIN, Maria S.S. Desenvolvimento moral: refletindo com pais e professores. In: MACEDO, Lino de (Org.). Cinco estudos de educação moral. São Paulo: Casa do Psicólogo, 1996.
NOVIKOFF, Cristina. As representações sociais acerca dos adolescentes: perspectivas e práticas pedagógicas em construção. 2002. Dissertação (Mestrado) Universidade do Estado do Rio de Janeiro, Rio de Janeiro, 2002.

PIAGET, Jean O juízo moral na criança. São Paulo: Summus Editorial, 1994. 302 p.

SASTRE, G.; MORENO, M. Resolução de conflitos e aprendizagem emocional: gênero e transversalidade. Tradução: Ana Venite Fuzatol. São Paulo: Moderna, 2002.

WEIL, P. A arte de viver em paz: uma nova consciência da paz. São Paulo: Gente, 1993. 